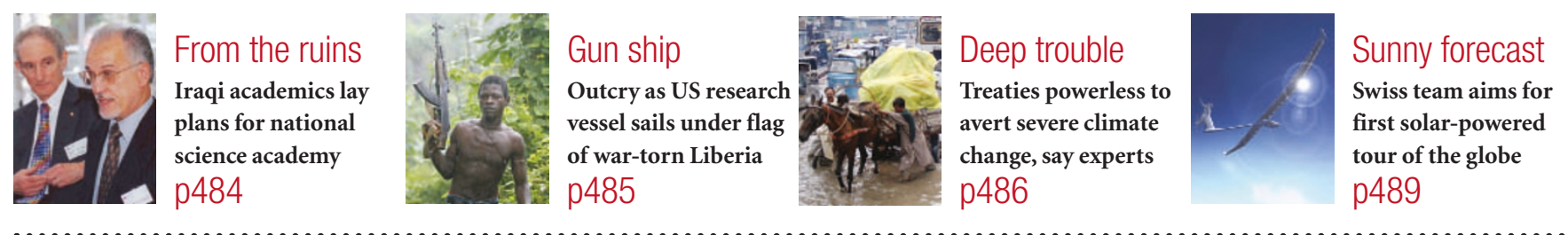

\title{
France and Japan lock horns in battle to host research reactor
}

\section{Declan Butler, Paris}

Japan and the European Union (EU) will this week contest rights to host the US\$5-billion ITER fusion experiment, after France saw off Spain's bid to be Europe's candidate. But uncertainty remains over whether the world's largest planned scientific project will proceed at all, researchers in several countries say.

Spanish negotiators had wanted the project's international partners to consider its own site near Barcelona, as well as France's site at Cadarache, near Marseille. But the EU last week unanimously backed the French site to compete with Japan's site at Rokkasho-Mura, $600 \mathrm{~km}$ north of Tokyo. A fourth site in Canada has effectively been withdrawn from the competition.

The ITER partners - the EU, Japan, Russia, Canada, China, South Korea and the United States - could choose the final winner as early as 5 December, when they meet in Vienna. Otherwise, a decision might be made when their representatives meet again in Washington on 16 December.

The ITER reactor aims to reproduce the thermonuclear fusion that powers the stars, heating a mix of deuterium and tritium, two isotopes of hydrogen, to 200 million ${ }^{\circ} \mathrm{C}$, in a doughnut-shaped reactor called a tokamak. The plasma mix would be suspended by superconducting magnets, while a fusion reaction generates $410 \mathrm{MW}$ of power for up to 500 seconds. ITER would be the first such reactor to sustain a power output comparable to the power that might be required in future fusion-based power stations.

Europe's choice of France could complicate the position of one partner - the United States - in what officials say have already been tense negotiations. The United States was officially 'neutral' on the European site decision, but Bush administration officials made little secret of the fact that they favoured Spain - an ally in the Iraq war over France (see Nature 423, 211;2003).

Scientists are keen that such political considerations stay out of the site choice, but as one US fusion researcher says: "US-French relations are strained. The issue is looming out there; you have to deal with it." Officials involved in negotiating the $\mathrm{EU}$ bid are

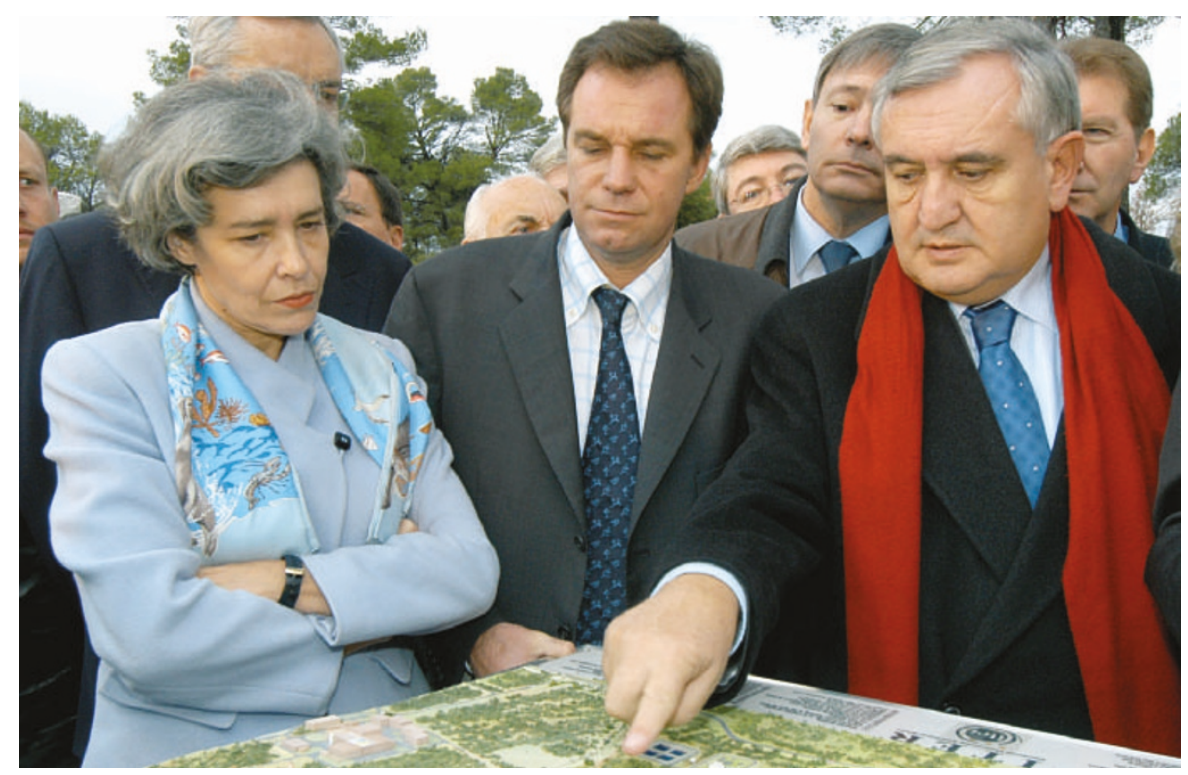

Prime minister Jean-Pierre Raffarin (right) and cabinet members examine France's plans for ITER.

equally keen to move on. As one of them puts it: "Cadarache is no longer a French candidate, it's a candidate of the EU, where there are strong US allies. So the United States wouldn't just be hurting one member state, but all."

But the negotiations have no simple voting rules, and officials and researchers say that the project probably needs a consensus from all partners to proceed. Failure in this month's talks could result in the entire project unravelling, they add. A breakdown in talks is "the lingering worry in the background", says one US fusion scientist. "I can see some of the rocks in the water."

A deal will involve consensus on engineering, costs, culture and politics, though perhaps not in that order. On paper, the French site has some advantages, such as existing onsite industrial and scientific nuclear capacity. But several fusion pundits said that Japan has the edge over Europe, because they think that it may be willing to spend more cash and it is close to ITER's new partners Korea and China. The amount of money each party is prepared to put on the table this week could sway the choice, they say.

Some US scientists privately told Nature that they would prefer to spend the next ten years working on the project in the south of France than in Japan. But any such individual preferences will probably be outweighed by broader, national interests, says Gerald Navratil, a fusion scientist at Columbia University in New York. "Japan may be the consensus site in that all are Pacific-rim nations except the EU," he says. "If political considerations include effective involvement of Korea and China and strengthening US ties in Asia, the United States may well go this way."

"We would hope to have their support because of our proximity," says Hiroshi Kishimoto, the ITER spokesman for the Japan Atomic Energy Research Institute.

For their part, scientists seem less concerned with the choice of site than with the risk that any disagreement could scupper ITER itself. "The highest priority for the US scientific community is that a decision should be made to move forward," says Robert Goldston, director of the Princeton Plasma Physics Laboratory in New Jersey, adding that he feels that the partners can build it whichever site is chosen. "Many of us in the community have worked for years, some for decades to bring us to this point," adds Navratil. "We may finally pull this off." 